\title{
Correlation of telomere length to malignancy potential in non-melanoma skin cancers
}

\author{
HANAE YAMADA-HISHIDA, YOSHIMASA NOBEYAMA and HIDEMI NAKAGAWA \\ Department of Dermatology, The Jikei University School of Medicine, Tokyo 105-8461, Japan
}

Received July 19, 2017; Accepted September 22, 2017

DOI: $10.3892 / \mathrm{ol} .2017 .7278$

\begin{abstract}
Telomeres are associated with cell fate and aging through their role in the cellular response to stress and growth stimulation resulting from previous cell divisions and DNA damage. Telomere shortening has been observed in most human cancers, and is known to be a feature of malignancy. The aim of this study is to clarify whether telomere length is related to the malignant potential of non-melanoma skin cancers. Telomere length was analyzed using tissue quantitative fluorescence in situ hybridization in 36 non-melanoma skin cancers including basal cell carcinoma (BCC), squamous cell carcinoma (SCC), Bowen's disease (BD) and actinic keratosis (AK), and also in 26 samples of normal-appearing epidermal tissue surrounding or located close to each tumor. The fluorescence intensities of telomeres and centromeres within nuclei were determined, and the telomere-centromere ratio (TCR) was then calculated in each sample. The resulting histograms suggested that the TCR values for each type of tumor cell were distributed in a lower range than those for epidermal cells located close to the corresponding tumor type, and that the TCR values for SCC and BCC cells were distributed in a lower range than those for $\mathrm{BD}$ and $\mathrm{AK}$ cells. These results were completely consistent with the potential for metastasis and invasion of each tumor type, suggesting that telomere length in non-melanoma skin cancer cells is intrinsically linked to their biological behavior.
\end{abstract}

\section{Introduction}

The telomere, located at the ends of eukaryotic chromosomes, is a structure composed of tandem repeats of a DNA sequence $\left(5^{\prime}-\mathrm{TTAGGG}-3^{\prime}\right)_{\mathrm{n}}$ together with specific binding proteins that

Correspondence to: Dr Yoshimasa Nobeyama, Department of Dermatology, The Jikei University School of Medicine, 3-28-8 Nishi-shimbashi, Minato-ku, Tokyo 105-8461, Japan E-mail: nobederm@jikei.ac.jp

Key words: telomere, tissue quantitative fluorescence in situ hybridization, non-melanoma skin cancer, squamous cell carcinoma, actinic keratosis, basal cell carcinoma, Bowen's disease function in telomere formation, protection and length maintenance $(1,2)$. The telomere repeat sequence becomes shortened at each cell division, or this may occur through DNA damage resulting from oxidative stress, or changes in telomere-associated proteins $(3,4)$. Telomeres play a central role in cell fate and aging by adjusting the cellular response to stress and growth stimulation that results from previous cell divisions and DNA damage; specifically, when telomeres have sufficient length, they are able to prevent DNA modification and chromosomal instability through DNA repair mechanisms at chromosome ends $(1,2)$. In fact, the presence of telomere repeats of a few hundred nucleotides at each chromosome end is needed to avoid activation of DNA repair pathways $(1,2)$. Somatic non-malignant cells with limited expression of human telomerase reverse transcriptase (hTERT) have a decreased capacity for repair, once telomeres have become critically shortened or lost, thus triggering apoptosis or cellular senescence $(1,2,5)$. It has been reported that telomeres and/or telomerase status are intimately involved in the pathogenesis of various cancers; cancer cells with impaired DNA damage responses (e.g., through loss of functional p53) continue to divide in the presence of dysfunctional telomeres, resulting in genome instability via chromosome fusions, chromosome breaks, and repetitive break-fusion bridge events $(1,6)$. Moreover, in cancer cells with hTERT expression, only a limited number of short ends can be elongated by hTERT, representing so-called 'telomere salvage pathways'. Telomere shortening and hTERT expression have been reported in various cancers and their precursor lesions including gastric cancer, thyroid cancer, bladder cancer, colon cancer, and ulcerative colitis (7-11). As a biological marker, telomere length reflects malignant potential, and might also be associated with genetic instability and the degree of malignancy risk (10).

Non-melanoma skin cancers including basal cell carcinoma (BCC), squamous cell carcinoma (SCC), Bowen's disease $(\mathrm{BD})$ and actinic keratosis $(\mathrm{AK})$ are the most common malignant skin tumors occurring world-wide (12). SCC is an epidermis-derived invasive malignancy characterized histopathologically by infiltration of atypical keratinocytes with occasional by some level of keratinization, that invade through the basement membrane into the dermis (13). BD is regarded as SCC in situ, being characterized histopathologically by atypical cellular pleomorphism including cell clumping, irregular mitosis and individual cell keratinization within the epidermis, and having the potential to transform 
into invasive SCC (14). AK is also regarded as an SCC in situ, characterized histopathologically by atypia or dysplasia of keratinocytes in the epidermal basal layers accompanied by dermal solar elastosis, having the potential to transform into invasive SCC (15). BCC is a non-keratinizing basal epidermal cell neoplasm and is characterized histopathologically by nests of basophilic epidermal basal cell-like cells with a peripheral palisading arrangement. $\mathrm{BCC}$ is regarded as a lineage that differs from $\mathrm{SCC}, \mathrm{BD}$ or $\mathrm{AK}$ in that $\mathrm{BD}$ and $\mathrm{AK}$ do not develop into $\mathrm{BCC}$, and $\mathrm{BCC}$ does not develop into SCC, except for a specific form of 'basosquamous cell carcinoma'. The metastatic potential of $\mathrm{AK}, \mathrm{BD}$ and $\mathrm{BCC}$ is almost zero, whereas the risk of SCC metastasis is estimated to be $0.1-13.7 \%$ (16). BCC and SCC, but not BD and AK, have invasion potential (13).

Several reports have described the telomere and telomerase status of non-melanoma skin cancers (17-20), as well as for various other malignancies. Wainwright $e t$ al reported that telomeres in BCC were not shortened in comparison to control epidermis (17). Parris et al reported that telomerase activity was increased in BD and AK but only minimally increased in SCC (18). Despite these studies, the association between telomeres/telomerase and the malignant potential of non-melanoma skin cancers has not been well documented.

The purpose of the present study was to determine whether telomere length has a relationship to the malignant potential of non-melanoma skin cancers. Our analysis demonstrated clear associations between the telomere lengths of various non-melanoma skin cancers and their malignant potential.

\section{Materials and methods}

Tissue specimens. Fresh tissue samples were obtained by trepan or scalpel from patients at the time of excisional surgery, and then immediately frozen. The samples comprised 36 non-melanoma skin cancers including 12 BCCs (patient age range, 48-92 year), 9 SCCs (41-96 year), 9 BDs (56-91 year) and 6 AKs (62-81 year), and 26 samples of epidermal tissue, each surrounding a corresponding tumor, including 9 BCCs (patient age range, 48-92 year), 6 SCCs (41-92 year), 6 BDs (56-91 year) and 5 AKs (62-81 year). The diagnoses were made histopathologically by more than one experienced board-certified dermatopathologist. All samples were collected at the Department of Dermatology, The Jikei University School of Medicine. For use of the clinical specimens, written informed consent was obtained from all reachable donors, as allowed by the ethics committee of The Jikei University School of Medicine.

Tissue quantitative florescence in situ hybridization $(Q$-FISH). Tissue Q-FISH was performed in accordance with previously described processing procedures (21-23). In brief, the samples were fixed for $2 \mathrm{~h}$ in $10 \%$ buffered formalin solution and then embedded in paraffin according to standard processing procedures. They were then cut into $5 \mu \mathrm{m}$-thick sections for tissue Q-FISH analysis. The tissue sections were deparaffinized in xylene, pre-treated with $0.2 \mathrm{~N} \mathrm{HCl}$ and $1.0 \mathrm{M}$ sodium thiocyanate at $80^{\circ} \mathrm{C}$, and then with $1.0 \%$ pepsin at $37^{\circ} \mathrm{C}$. They were also treated with $0.5 \mathrm{mg} / \mathrm{ml}$ RNase at $37^{\circ} \mathrm{C}$ to remove RNA. A peptide nucleic acid (PNA) telomere probe conjugated to $\mathrm{Cy} 3$ (Telo $\mathrm{C}-\mathrm{Cy} 3$ probe: 5'-CCCTAA CCCTAACCCTAA-3', Fasmac, Atsugi, Japan) and a PNA centromere probe conjugated to fluorescein isothiocyanate (FITC) (Cenp 1 probe: 5'-CTTCGTTGGAAACGGGGT-3', Fasmac) were applied to each section. The nuclei were stained with 4',6-diamidino-2-phenylindole (DAPI) (Sigma-Aldrich; Merck KGaA, Darmstadt, Germany).

FISH images were captured by a charge-coupled device camera attached to an epifluorescence microscope (Eclipse 90i; Nikon, Tokyo, Japan) equipped with a triple band-pass filter set for DAPI/FITC/Cy3 (61000v2 m; Chroma Technology Corp., Rockingham, VT, USA) and a 440 objective lens (Plan Fluor x40/0.75; Nikon). Microscope control and image recording were performed using Image-Pro Plus software (version 7.01; Media Cybernetics, Bethesda, MD, USA). The recorded images were analyzed using an original software package, 'Tissue Telo Version 3.2', which allows manual identification of nuclear regions from the composite color image: DAPI (blue channel), FITC (green), and Cy3 (red). Fluorescence intensities of telomere signals (Cy3) and centromere signals (FITC) for each nucleus were measured. The telomere-centromere ratio (TCR) was then calculated, because there is no guarantee that all information regarding telomere signals will be acquired within any given tissue section.

Statistical analysis. Statistical analysis was performed with the 'SPSS statistics 23' software package. Normality of each mean TCR value was confirmed by the Kolmogorov-Smirnov test. Equality of variance was examined by Levene's test. The association between TCR and clinical information was examined by multiple linear regression analysis. The significance of differences among mean TCR values was examined by one-way analysis of variance and Bonferroni's multiple comparisons test when both normality and equality of variance were confirmed, and by the Kruskal-Wallis test when either normality or equality was not confirmed. $\mathrm{P}<0.05$ was considered to indicate a statistically significant difference.

\section{Results}

FISH analyses detected telomeres and centromeres as small red and green dots, respectively, within nuclei (Fig. 1). Telomere signals of BCC, SCC, BD and AK tumor cells appeared to be weaker than those of the epidermal cells located close to the respective tumors in most samples. Captured FISH images were quantified (Table I), yielding in a mean TCR value \pm standard deviation for tumor cells of BCC, SCC, BD and AK of $3.02 \pm 2.05,2.01 \pm 1.86,3.97 \pm 2.51$ and $4.04 \pm 2.47$, respectively, and corresponding values for epidermal cells located close to the tumors of $3.87 \pm 2.39,4.20 \pm 2.51,4.86 \pm 2.63$ and $4.48 \pm 2.55$, respectively. Histograms showing the distribution of TCR values for each type of tumor cell and the corresponding closely located epidermal cells were constructed based on the quantified FISH images (Fig. 2). These histograms showed that the peak frequency of TCR in BCC cells was closed to $1-2$, whereas that in SCC cells was $<1$. It was also evident that TCR values for SCC and BCC cells were distributed within a lower range than those for $\mathrm{BD}$ and $\mathrm{AK}$ cells. TCR values for 

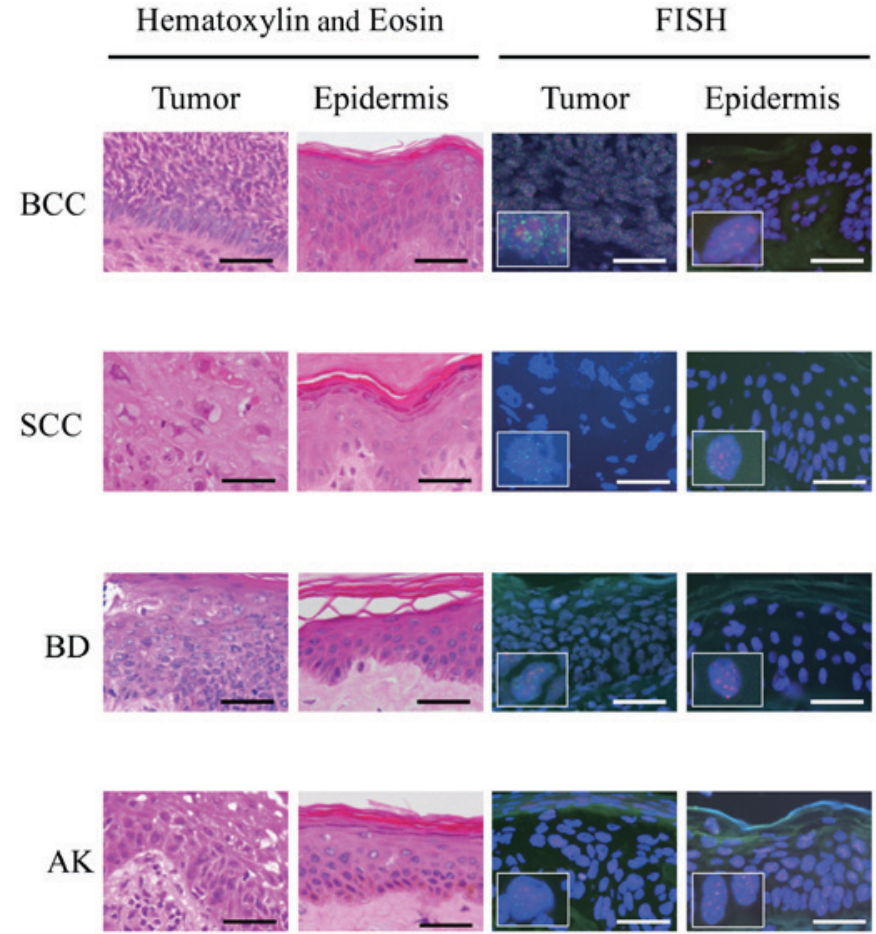

Figure 1. Representative images of hematoxylin and eosin-stained sections and FISH images of BCC (patient no. 1), SCC (patient no. 17), BD (patient no. 23) and AK (patient no. 31). The scale bar in the lower right corner in each image indicates $40 \mu \mathrm{m}$. 'Tumor' indicates representative images for each tumor. 'Epidermis' indicates representative images of epidermal tissue located close to each tumor. Magnified images in the left corner of the FISH images are provided for more detailed observation of red and green dots within the cell. In the FISH images, red dots (Cy3) and green dots (fluorescein isothiocyanate) within nuclei indicate telomere and centromere signals, respectively. FISH, fluorescence in situ hybridization; BSS, Basal cell carcinoma; SCC, squamous cell carcinoma; BD, Bowen's disease; AK, actinic keratosis.

epidermal cells located close to each tumor type had a very wide distribution, and the peak frequency was $\geq 2$. TCR values for each type of tumor cell appeared to be distributed within a lower range than those of the corresponding closely located epidermal cells.

To analyze the association between the TCR values for the various types of tumor cells and clinical parameters including patient age, sex, sampling site (sites chronically or non-chronically exposed to the sun) and the TCR values for epidermal cells located close to each tumor type, multiple linear regression analyses were performed using the TCR value for each type of tumor cell as the dependent variable (Table II). These statistical analyses indicated that the TCR value for each type of tumor cell was not associated with patient age, sex, sampling site or the TCR value of the epidermal cells located close to each tumor type. To analyze the association between the TCR value of the epidermal cells close to each type of tumor and clinical parameters including patient age, sex, sampling site (chronically or non-chronically exposed to the sun) and the TCR value for each type of tumor cell, multiple linear regression analyses were performed using the TCR value of the closely located epidermal cells as the dependent variable (Table II). These statistical analyses indicated that the TCR value for the epidermal cells located close to each type of tumor were not associated with patient age, sex, sampling site or the TCR value for each type of tumor cell.

To compare TCR values among BCC, SCC, BD and AK tumors, one-way analysis of variance followed by Bonferroni's multiple comparison test was performed for each type of tumor cell whose distribution showed both normality and equality of variance (Table III). These analyses showed that the TCR values for SCC were significantly lower than those for $\mathrm{BCC}, \mathrm{BD}$ or $\mathrm{AK}$, and that the TCR values for BCC were significantly lower than those for $\mathrm{BD}$. To compare the TCR values for epidermal cells located close to BCC, SCC, BD and AK tumors, the Kruskal-Wallis test was performed for cases where the distribution did not show equality of variance. These analyses showed that the TCR values for epidermal cells located close to each tumor were not associated with the tumor type. To confirm these results, multiple linear regression analyses were performed (Table IV), and this demonstrated that i) the TCR values for SCC or BCC were significantly lower than those for BD or AK; ii) the TCR values for BCC, $\mathrm{BD}$ or $\mathrm{AK}$ were significantly higher than those for SCC; and iii) the TCR values for epidermal cells located close to each tumor type were not associated with the type of tumor cell. These results were compatible with those of one-way analysis of variance or Kruskal-Wallis test.

\section{Discussion}

In the present study, we employed the tissue Q-FISH method for the determination of telomere length. This approach has some merits for evaluation of telomeres because it independently measures the fluorescence intensity of the telomere and that of the centromere, the latter being used as a standard whose reliability as an accurate internal control parameter has been confirmed by numerous previous studies (21-23). This allowed us to obtain the telomere-centromere ratio (TCR), which has been shown to reflect telomere length more accurately than procedures that lack an internal control (21-23). Data on telomere length can be obtained in this way by performing in situ hybridization on histological sections, allowing specific evaluation of cancer cells or the cells surrounding the tumor on tissue sections, which commonly include a number of other cell types such as inflammatory cells. Several previous studies have investigated telomeres in esophageal, breast, and thyroid cancers using tissue Q-FISH, and the results obtained were very similar to ours in terms of the TCR distributions of tumor cells and the cells surrounding tumors. As was seen in our present study, the TCR distribution shown in previous studies peaked at a value of $<1.0$ for cancer cells and $>1.0$ for tumor-surrounding cells. Additionally, the TCR distributions of cells with normal appearance surrounding the tumor cells showed a wide distribution similar to that of the epidermal cells close to each tumor in our present study (22-25). These findings suggest that tissue Q-FISH is a reliable procedure for determining the telomere length of solid cancers including skin cancers.

The present study represents the first comprehensive examination of telomere length in non-melanoma skin cancers, including the lineages of epidermis-derived cancers, i.e., AK-SCC and BD-SCC. Our findings suggest that telomere length in non-melanoma skin cancer cells is 
Table I. Clinical data for patients who donated samples.

\begin{tabular}{|c|c|c|c|c|c|c|c|c|c|}
\hline \multirow[b]{2}{*}{ ID } & \multirow[b]{2}{*}{ Age } & \multirow[b]{2}{*}{ Sex } & \multirow[b]{2}{*}{ Sample $^{\mathrm{a}}$} & \multirow[b]{2}{*}{ Diagnosis } & \multirow[b]{2}{*}{$\mathrm{TNM}^{\mathrm{b}}$} & \multirow[b]{2}{*}{$\mathrm{F} / \mathrm{U}^{\mathrm{c}}$} & \multirow[b]{2}{*}{ Rec. $^{d}$} & \multicolumn{2}{|c|}{ Average TCR value } \\
\hline & & & & & & & & Tumor & Epidermis ${ }^{\mathrm{e}}$ \\
\hline No. 1 & 48 & M & Face & $\mathrm{BCC}$ & pT2N0M0 & 5 & + & $2.54 \pm 1.58$ & $4.39 \pm 2.34$ \\
\hline No. 2 & 83 & $\mathrm{~F}$ & Face & $\mathrm{BCC}$ & pT1N0M0 & 65 & - & $4.22 \pm 2.32$ & $4.54 \pm 2.28$ \\
\hline No. 3 & 92 & M & Face & $\mathrm{BCC}$ & pT1N0M0 & 8 & - & $4.81 \pm 2.29$ & $5.24 \pm 2.58$ \\
\hline No. 4 & 73 & $\mathrm{~F}$ & Face & $\mathrm{BCC}$ & pT1N0M0 & 48 & - & $3.18 \pm 2.18$ & $4.50 \pm 2.61$ \\
\hline No. 5 & 77 & M & Face & $\mathrm{BCC}$ & pT2N0M0 & 40 & - & $3.42 \pm 2.03$ & nd \\
\hline No. 6 & 73 & M & Face & $\mathrm{BCC}$ & pT1N0M0 & 0 & - & $3.56 \pm 2.27$ & nd \\
\hline No. 7 & 84 & M & Face & $\mathrm{BCC}$ & pT2N0M0 & 49 & - & $2.19 \pm 1.32$ & $2.93 \pm 2.01$ \\
\hline No. 8 & 77 & M & Face & $\mathrm{BCC}$ & pT2NOM0 & 35 & - & $2.21 \pm 1.63$ & $2.88 \pm 2.04$ \\
\hline No. 9 & 79 & M & Face & $\mathrm{BCC}$ & pT1N0M0 & 8 & - & $2.52 \pm 1.85$ & nd \\
\hline No. 10 & 80 & M & Face & $\mathrm{BCC}$ & pT1N0M0 & 0 & - & $2.78 \pm 2.04$ & $3.34 \pm 2.07$ \\
\hline No. 11 & 73 & $\mathrm{~F}$ & Trunk & $\mathrm{BCC}$ & pT2NOM0 & 12 & - & $2.43 \pm 2.05$ & $5.00 \pm 2.48$ \\
\hline No. 12 & 68 & $\mathrm{~F}$ & Face & $\mathrm{BCC}$ & pT1N0M0 & 53 & - & $2.89 \pm 1.98$ & $3.40 \pm 2.10$ \\
\hline No. 13 & 92 & $\mathrm{~F}$ & Face & $\mathrm{SCC}$ & pT1N0M0 & 16 & + & $1.47 \pm 1.16$ & $2.47 \pm 1.62$ \\
\hline No. 14 & 87 & $\mathrm{~F}$ & Face & $\mathrm{SCC}$ & pT1N0M0 & 63 & - & $0.91 \pm 0.91$ & $5.69 \pm 2.42$ \\
\hline No. 15 & 96 & $\mathrm{~F}$ & Hand & $\mathrm{SCC}$ & pT1N0M0 & 14 & + & $3.62 \pm 2.31$ & $4.75 \pm 2.58$ \\
\hline No. 16 & 52 & $\mathrm{M}$ & Genitalia & SCC & pT1N0M0 & 51 & - & $2.52 \pm 1.90$ & $5.09 \pm 2.49$ \\
\hline No. 17 & 41 & $\mathrm{M}$ & Hand & SCC & pT1N0M0 & 25 & - & $2.15 \pm 1.72$ & $4.65 \pm 2.37$ \\
\hline No. 18 & 92 & M & Thigh & $\mathrm{SCC}$ & pT1N0M0 & 12 & - & $2.07 \pm 1.96$ & $4.10 \pm 2.32$ \\
\hline No. 19 & 96 & $\mathrm{~F}$ & Hand & $\mathrm{SCC}$ & pT2N0M0 & 11 & - & $0.80 \pm 0.59$ & nd \\
\hline No. 20 & 94 & $\mathrm{~F}$ & Foot & $\mathrm{SCC}$ & pT2NOM0 & 20 & - & $1.06 \pm 0.87$ & nd \\
\hline No. 21 & 89 & M & Face & $\mathrm{SCC}$ & pT1N0M0 & 8 & + & $0.67 \pm 0.70$ & nd \\
\hline No. 22 & 88 & $\mathrm{~F}$ & Genitalia & $\mathrm{BD}$ & pTisN0M0 & 0 & - & $3.78 \pm 2.33$ & nd \\
\hline No. 23 & 89 & $\mathrm{~F}$ & Thigh & $\mathrm{BD}$ & pTisN0M0 & 11 & - & $5.26 \pm 2.42$ & $4.79 \pm 2.69$ \\
\hline No. 24 & 56 & $\mathrm{~F}$ & Forearm & $\mathrm{BD}$ & pTisN0M0 & 35 & - & $4.89 \pm 3.05$ & $5.22 \pm 2.66$ \\
\hline No. 25 & 66 & $\mathrm{~F}$ & Knee & $\mathrm{BD}$ & pTisN0M0 & 45 & - & $3.22 \pm 2.40$ & nd \\
\hline No. 26 & 72 & M & Trunk & $\mathrm{BD}$ & pTisN0M0 & 1 & - & $3.07 \pm 1.96$ & nd \\
\hline No. 27 & 91 & M & Face & $\mathrm{BD}$ & pTisN0M0 & 7 & - & $4.85 \pm 2.37$ & $5.04 \pm 2.29$ \\
\hline No. 28 & 70 & M & Thigh & BD & pTisN0M0 & 12 & - & $4.02 \pm 2.66$ & $4.61 \pm 2.78$ \\
\hline No. 29 & 58 & $\mathrm{~F}$ & Trunk & BD & pTisN0M0 & 0 & - & $4.45 \pm 2.52$ & $4.84 \pm 2.68$ \\
\hline No. 30 & 57 & $\mathrm{~F}$ & Thigh & $\mathrm{BD}$ & pTisN0M0 & 2 & - & $4.53 \pm 2.49$ & $4.92 \pm 2.71$ \\
\hline No. 31 & 67 & M & Face & AK & pTisN0M0 & 0 & - & $3.69 \pm 2.26$ & $4.72 \pm 2.42$ \\
\hline No. 32 & 71 & $\mathrm{M}$ & Face & AK & pTisN0M0 & 28 & - & $4.75 \pm 2.45$ & $5.00 \pm 2.38$ \\
\hline No. 33 & 62 & M & Face & $\mathrm{AK}$ & pTisN0M0 & 11 & - & $4.93 \pm 2.53$ & $4.78 \pm 2.66$ \\
\hline No. 34 & 81 & M & Face & AK & pTisN0M0 & 45 & + & $4.49 \pm 2.75$ & $3.57 \pm 2.50$ \\
\hline No. 35 & 80 & $\mathrm{M}$ & Face & $\mathrm{AK}$ & pTisN0M0 & 13 & - & $1.76 \pm 2.19$ & nd \\
\hline No. 36 & 73 & M & Face & AK & pTisN0M0 & 1 & - & $4.66 \pm 2.76$ & $4.49 \pm 2.49$ \\
\hline
\end{tabular}

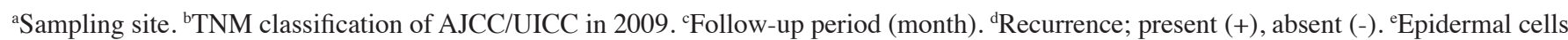
close to each tumor. nd, not done; TCR, telomere-centromere ratio.

intrinsically related to aspects of biological behavior including the potential for metastasis and invasion. Use of two different statistical analyses, i.e., multiple linear regression analysis and Bonferroni's multiple comparison test, yielded similar results in terms of the TCR values for the various types of tumor cells; i.e., these TCR values showed the order $\mathrm{SCC}<\mathrm{BCC}<\mathrm{BD}$ or AK. These TCR values were completely consistent with the metastatic potential of the tumors; SCC, BCC and BD/AK have some, minimal and no metastatic potential, respectively. In this context, the metastatic potential of non-melanoma skin cancers could be associated with telomere length, and thus evaluable by the TCR value, although we did not investigate variation in metastatic potential within a single type of tumor. In addition, $\mathrm{BCC}$ has a distinct tendency to invade to the deeper levels including the dermis, whereas BD/AK has no invasion potential, suggesting that telomere length could also be associated with the invasion potential of non-melanoma skin cancers, and thus evaluable by the TCR value, although we did not investigate difference in invasion potential within a single tumor type. 
Table II. Results of multiple regression analysis with TCR as the dependent variable.

\begin{tabular}{|c|c|c|c|c|}
\hline \multirow[b]{2}{*}{ Independent variable } & \multicolumn{2}{|c|}{ Tumor } & \multicolumn{2}{|c|}{ Epidermis $^{c}$} \\
\hline & $\beta$-value ${ }^{\mathrm{b}}$ & P-value & $\beta$-value ${ }^{b}$ & P-value \\
\hline Age & 0.162 & 0.208 & -0.264 & 0.194 \\
\hline Sex & 0.002 & 0.988 & -0.125 & 0.561 \\
\hline Chronic sun-exposure ${ }^{a}$ & 0.076 & 0.600 & -0.133 & 0.564 \\
\hline TCR values for epidermis & 0.277 & 0.053 & & \\
\hline TCR values for tumor & & & 0.695 & 0.053 \\
\hline
\end{tabular}

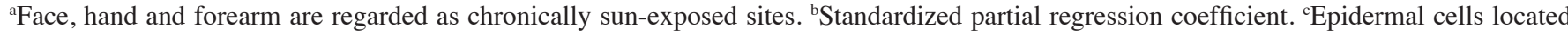
close to each tumor. TCR, telomere-centromere ratio.

Table III. Results of Bonferroni's multiple comparison test.

\begin{tabular}{lc}
\hline Comparison of TCR values & P-value \\
\hline BCC vs. AK & 0.236 \\
BCC vs. BD & $0.041^{\mathrm{a}}$ \\
BCC vs. SCC & $0.011^{\mathrm{a}}$ \\
SCC vs. AK & $<0.001^{\mathrm{a}}$ \\
SCC vs. BD & $<0.001^{\mathrm{a}}$ \\
BD vs. AK & 1.000
\end{tabular}

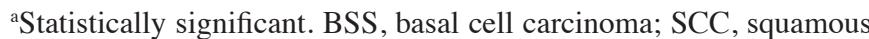
cell carcinoma; BD, Bowen's disease; AK, actinic keratosis; TCR, telomere-centromere ratio.

Table IV. Comparison among TCR values by multiple regression analysis.

\begin{tabular}{|c|c|c|c|c|}
\hline \multirow[b]{2}{*}{ Independent variable } & \multicolumn{2}{|c|}{ Tumor } & \multicolumn{2}{|c|}{ Epidermis $^{\mathrm{e}}$} \\
\hline & $\beta$-value ${ }^{\mathrm{f}}$ & P-value & $\beta$-value ${ }^{f}$ & P-value \\
\hline SCC vs. BCC ${ }^{a}$ & -0.362 & $0.018^{\mathrm{g}}$ & 0.418 & 0.098 \\
\hline BD vs. BCC ${ }^{a}$ & 0.498 & $0.007^{\mathrm{g}}$ & -0.062 & 0.864 \\
\hline AK vs. $\mathrm{BCC}^{\mathrm{a}}$ & 0.418 & $0.010^{\mathrm{g}}$ & -0.064 & 0.820 \\
\hline BCC vs. $\mathrm{SCC}^{\mathrm{b}}$ & 0.409 & $0.018^{\mathrm{g}}$ & -0.472 & 0.098 \\
\hline BD vs. $\mathrm{SCC}^{\mathrm{b}}$ & 0.860 & $<0.001^{\mathrm{g}}$ & -0.480 & 0.233 \\
\hline AK vs. SCC & 0.757 & $<0.001^{\mathrm{g}}$ & -0.455 & 0.227 \\
\hline $\mathrm{BCC}$ vs. $\mathrm{BD}^{\mathrm{c}}$ & -0.562 & $0.007^{\mathrm{g}}$ & 0.070 & 0.846 \\
\hline $\mathrm{SCC}$ vs. BD ${ }^{\mathrm{c}}$ & -0.860 & $<0.001^{\mathrm{g}}$ & 0.480 & 0.233 \\
\hline AK vs. BD ${ }^{c}$ & -0.048 & 0.793 & -0.006 & 0.984 \\
\hline BCC vs. $\mathrm{AK}^{\mathrm{d}}$ & -0.504 & $0.010^{\mathrm{g}}$ & 0.078 & 0.820 \\
\hline SCC vs. $\mathrm{AK}^{\mathrm{d}}$ & -0.809 & $<0.001^{\mathrm{g}}$ & 0.487 & 0.227 \\
\hline $\mathrm{BD}$ vs. $\mathrm{AK}^{\mathrm{d}}$ & 0.051 & 0.793 & 0.006 & 0.984 \\
\hline
\end{tabular}

Standardized by TCR values of $\mathrm{BCC}^{\mathrm{a}}, \mathrm{SCC}^{\mathrm{b}}, \mathrm{BD}^{\mathrm{c}}$ or $\mathrm{AK}^{\mathrm{d}} .{ }^{\mathrm{e}}$ Epidermal

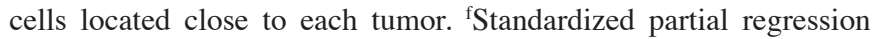
coefficient. ${ }^{g}$ Statistically significant. BSS, basal cell carcinoma; SCC, squamous cell carcinoma; BD, Bowen's disease; AK, actinic keratosis; TCR, telomere-centromere ratio.
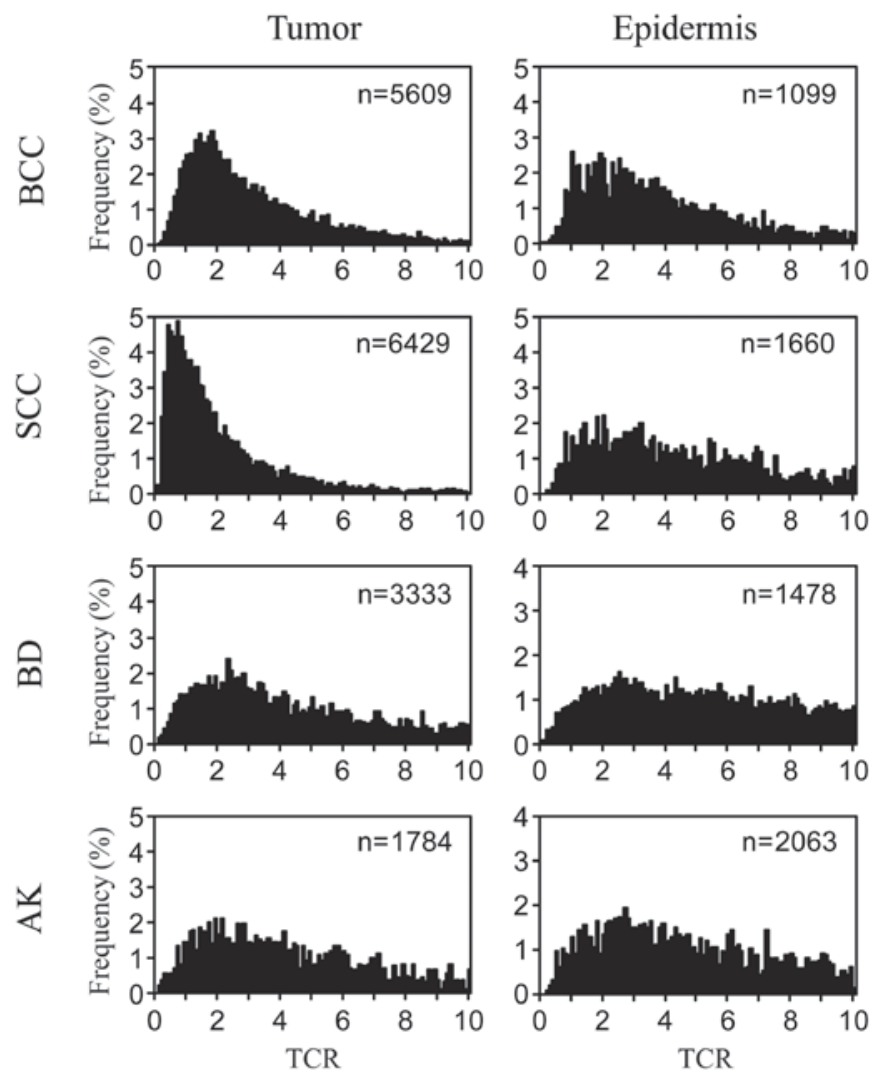

Figure 2. Histograms of TCR distribution in tumor cells of BCC, SCC, BD, $\mathrm{AK}$ and their corresponding epidermal cells close to each type of tumor. The number of analyzed nuclei (n) is indicated in each histogram. 'Tumor' indicates histograms of each tumor. 'Epidermis' indicates histograms for epidermal tissue located close to each type of tumor. BSS, basal cell carcinoma; SCC, squamous cell carcinoma; BD, Bowen's disease; AK, actinic keratosis; TCR, telomere-centromere ratio.

Our statistical analyses suggested that the TCR values for epidermal cells located close to each tumor were not associated with patient age, sex, tumor type or sampling site (i.e., chronically or non-chronically exposed to solar radiation). It has been reported previously that TCR values for epidermal cells are reduced with increasing age and chronic sun-exposure $(26,27)$. There are a number of possible explanations for the discrepancy between the present results and the previous ones. The 
epidermal cells examined in the present study were located very close to each tumor, and therefore were likely to have been sampled from areas with field defects, which can be regarded as precursors of malignancy even though they often appear to be histopathologically normal. In contrast, the 'control' epidermal cells examined in previous studies were probably sampled from areas without field defects. Any subtle differences in TCR values resulting from age or chronic sun exposure might be masked by the effects of field defects, which might be associated with low TCR $(28,29)$.

Several previous studies have suggested that invasive SCC develops through stepwise progression, i.e., some invasive SCCs develop from AK (30-32). However, on the basis of DNA microarray profiling of over 47,000 genes, Ra et al have concluded that AK and SCC are distinct entities, since each has its own unique molecular signature (33). Our present finding that telomere length in SCC was significantly shorter than that in $\mathrm{BD}$ or $\mathrm{AK}$ suggests that these entities may be biologically distinct from one another. Our present finding also suggests that telomere shortening is correlated with invasive progression, thus being a useful parameter for distinguishing SCC from other tumors.

The limitation of the present study was the small number of samples employed. In order to examine more accurately the difference in telomere length between $\mathrm{BD}$ and $\mathrm{AK}$, a larger number of samples might be needed. Another limitation was that none of the epidermal samples were taken from areas that were distant from the tumor. Comparison of the TCRs of epidermal cells in areas close to the tumor with those of cells located distant from the tumor would likely show that causable field defects in non-melanoma skin cancer are caused, at least in part, by telomere shortening.

In conclusion, our comprehensive examination suggests that the telomere length of non-melanoma skin cancer cells is closely related to biological behavior including the potential for metastasis and invasion.

\section{Acknowledgements}

We thank Dr. Yoshiyuki Sugishita (Department of Laboratory, Kanaji Thyroid Hospital), Dr. Makoto Kammori, Dr. Ryoichi Kamide (Hihuno Clinic), and Dr Mariko Honda (Dr. Mariko Skin and Dermatology Clinic) for providing technical support or expert advice.

\section{References}

1. Aubert G and Lansdorp PM: Telomeres and aging. Physiol Rev 88: 557-579, 2008.

2. Blackburn EH: Switching and signaling at the telomere. Cell 106: 661-673, 2001.

3. Harley CB, Futcher AB and Greider CW: Telomeres shorten during ageing of human fibroblasts. Nature 345: 458-460, 1990.

4. von Zglinicki T: Oxidative stress shortens telomeres. Trends Biochem Sci 27: 339-344, 2002.

5. Artandi SE and DePinho RA: Telomeres and telomerase in cancer. Carcinogenesis 31: 9-18, 2010.

6. Blasco MA: Telomeres and human disease: Ageing, cancer and beyond. Nat Rev Genet 6: 611-622, 2005.

7. Furugori E, Hirayama R, Nakamura KI, Kammori M, Esaki Y and Takubo K: Telomere shortening in gastric carcinoma with aging despite telomerase activation. J Cancer Res Clin Oncol 126: 481-485, 2000.
8. Kammori M, Takubo K, Nakamura K, Furugouri E, Endo H, Kanauchi H, Mimura Y and Kaminishi M: Telomerase activity and telomere length in benign and malignant human thyroid tissues. Cancer Lett 159: 175-181, 2000

9. Broberg K, Björk J, Paulsson K, Höglund $M$ and Albin M: Constitutional short telomeres are strong genetic susceptibility markers for bladder cancer. Carcinogenesis 26: 1263-1271, 2005.

10. Nakamura K, Furugori E, Esaki Y, Arai T, Sawabe M, Okayasu I, Fujiwara M, Kammori M, Mafune K, Kato M, et al: Correlation of telomere lengths in normal and cancers tissue in the large bowel. Cancer Lett 158: 179-184, 2000.

11. O'Sullivan JN, Bronner MP, Brentnall TA, Finley JC, Shen WT, Emerson S, Emond MJ, Gollahon KA, Moskovitz AH, Crispin DA, et al: Chromosomal instability in ulcerative colitis is related to telomere shortening. Nat Genet 32: 280-284, 2002.

12. Firnhaber JM: Diagnosis and treatment of Basal cell and squamous cell carcinoma. Am Fam Physician 86: 161-168, 2012.

13. Yanofsky VR, Mercer SE and Phelps RG: Histopathological variants of cutaneous squamous cell carcinoma: A review. J Skin Cancer 2011: 210813, 2011.

14. Röwert-Huber J, Patel MJ, Forschner T, Ulrich C, Eberle J, Kerl H, Sterry W and Stockfleth E: Actinic keratosis is an early in situ squamous cell carcinoma: A proposal for reclassification. Br J Dermatol 3 (156 Suppl): S8-S12, 2007.

15. Glogau RG: The risk of progression to invasive disease. J Am Acad Dermatol 42: 23-24, 2000.

16. Kim RH and Armstrong AW: Nonmelanoma skin cancer. Dermatol Clin 30: 125-139, 2012.

17. Wainwright LJ, Middleton PG and Rees JL: Changes in mean telomere length in basal cell carcinomas of the skin. Genes Chromosomes Cancer 12: 45-49, 1995.

18. Parris CN, Jezzard S, Silver A, MacKie R, McGregor JM and Newbold RF: Telomerase activity in melanoma and non-melanoma skin cancer. Br J Cancer 79: 47-53, 1999.

19. Han J, Qureshi AA, Prescott J, Guo Q, Ye L, Hunter DJ and De Vivo I: A prospective study of telomere length and the risk of skin cancer. J Invest Dermatol 129: 415-421, 2009.

20. Leufke C, Leykauf J, Krunic D, Jauch A, Holtgreve-Grez H, Böhm-Steuer B, Bröcker EB, Mauch C, Utikal J, Hartschuh W, et al: The telomere profile distinguishes two classes of genetically distinct cutaneous squamous cell carcinomas. Oncogene 33:3506-3518, 2014

21. Aida J, Izumiyama-Shimomura N, Nakamura K, Ishii A, Ishikawa N, Honma N, Kurabayashi R, Kammori M, Poon SS and Arai T: Telomere length variations in 6 mucosal cell types of gastric tissue observed using a novel quantitative fluorescence in situ hybridization method. Hum Pathol 38: 1192-1200, 2007.

22. Kammori M, Izumiyama N, Nakamura K, Kurabayashi R, Kashio M, Aida J, Poon SS and Kaminishi M: Telomere metabolism and diagnostic demonstration of telomere measurement in the human esophagus for distinguishing benign from malignant tissue by tissue quantitative fluorescence in situ hybridization. Oncology 71: 430-436, 2006

23. Sugishita Y, Kammori M, Yamada O, Yamazaki K, Ito K, Fukumori T, Yoshikawa K and Yamada T: Biological differential diagnosis of follicular thyroid tumor and Hurthle cell tumor on the basis of telomere length and hTERT expression. Ann Surg Oncol 21: 2318-2325, 2014.

24. Kurabayashi R, Takubo K, Aida J, Honma N, Poon SS, Kammori M, Izumiyama-Shimomura N, Nakamura K, Tsuji E, Matsuura M, et al: Luminal and cancer cells in the breast show more rapid telomere shortening than myoepithelial cells and fibroblasts. Hum Pathol 39: 1647-1655, 2008.

25. Sugishita Y, Kammori M, Yamada O, Poon SS, Kobayashi M, Onoda N, Yamazaki K, Fukumori T, Yoshikawa K, Onose H, et al: Amplification of the human epidermal growth factor receptor 2 gene in differentiated thyroid cancer correlates with telomere shortening. Int J Oncol 42: 1589-1596, 2013.

26. Ikeda H, Aida J, Hatamochi A, Hamasaki Y, Izumiyama-Shimomura N, Nakamura K, Ishikawa N, Poon SS, Fujiwara M, Tomita K, et al: Quantitative fluorescence in situ hybridization measurement of telomere length in skin with/without sun exposure or actinic keratosis. Hum Pathol 45: 473-480, 2014.

27. Buckingham EM and Klingelhutz AJ: The role of telomeres in the ageing of human skin. Exp Dermatol 20: 297-302, 2011.

28. Aida J, Izumo T, Shimomura N, Nakamura K, Ishikawa N, Matsuura M, Poon SS, Fujiwara M, Sawabe M, Arai T and Takubo K: Telomere lengths in the oral epithelia with and without carcinoma. Eur J Cancer 46: 430-438, 2010. 
29. Kuhn E, Meeker A, Wang TL, Sehdev AS, Kurman RJ and Shih Ie M: Shortened telomeres in serous tubal intraepithelial carcinoma: An early event in ovarian high-grade serous carcinogenesis. Am J Surg Pathol 34: 829-836, 2010.

30. Czarnecki D, Meehan CJ, Bruce F and Culjak G: The majority of cutaneous squamous cell carcinomas arise in actinic keratoses. J Cutan Med Surg 6: 207-209, 2002.

31. Fu W and Cockerell CJ: The actinic (solar) keratosis: A 21st-century perspective. Arch Dermatol 139: 66-70, 2003.
32. Cassarino DS, Derienzo DP and Barr RJ: Cutaneous squamous cell carcinoma: A comprehensive clinicopathologic classification-part two. J Cutan Pathol 33: 261-279, 2006.

33. Ra SH, Li X and Binder S: Molecular discrimination of cutaneous squamous cell carcinoma from actinic keratosis and normal skin. Mod Pathol 24: 963-973, 2011. 